\title{
O conceito de divisão no modo de organização do ensino proposto por davýdov e colaboradores
}

\author{
Josélia Euzébio da Rosa \\ UNISUL - Universidade do Sul de Santa Catarina \\ joselia.euzebio@yahoo.com.br \\ Sandra Crestani \\ UNISUL - Universidade do Sul de Santa Catarina \\ sandra_crestani@hotmail.com
}

\begin{abstract}
Resumo
Investigamos o modo de organização de ensino proposto por Davýdov com a finalidade de promover o desenvolvimento do pensamento teórico dos estudantes por meio da apropriação dos conceitos científicos. Davýdov propõe que o ensino seja organizado por meio de tarefas de estudos, constituídas de seis ações, cujo desenvolvimento ocorre durante a resolução de um sistema de tarefas particulares. Em sua concepção, todos os conceitos são constituídos por uma relação universal. Nessa proposição, em uma pesquisa de caráter bibliográfico, analisamos as manifestações da relação universal do conceito de divisão. Constatamos que tal relação é revelada no movimento de modelação que segue do plano objetal ao gráfico e literal por meio da unidade básica, intermediária e o total de ambas. A gênese do conceito, na interconexão desses elementos, desencadeia um movimento conceitual orientado do geral para o particular e singular por meio da inter-relação das significações algébricas, geométricas e aritméticas.
\end{abstract}

Palavras-chave: Teoria Histórico-Cultural. Davýdov. Modo de organização do ensino. Conceito de Divisão.

\section{Division concept on the organization way proposed by Davýdov and coworkers}

\begin{abstract}
We investigated the teaching organization mode proposed by Davýdov in order to promote the development of Theoretical thinking in students through the scientifical concepts appropriation. Davýdov proposed the teaching organized by study tasks constituted of six actions, whose development occurs during the resolution of a particular task system. In his conception, all the concepts are constituted by a universal relationship. In this proposition and in a bibliographic research, we analyzed manifestations of universal relationship of the division concept. We noticed out that this relationship is revealed on the modeling movement that follows from the object plan to Graphic and literal through the basic and intermediate unit and of total of both. The genesis of the
\end{abstract}


concept in the interconnection of these elements triggers a conceptual movement guided from thegeneral to the particular and singular through the interrelation of algebraic, geometric and arithmetic meanings.

Keywords: Historical-Cultural Theory. Davýdov. Teaching organization way. Concept of Division.

\section{Introdução}

Diante do contexto atual da educação em nosso país almejamos, com a presente pesquisa, contribuir para as reflexões sobre o modo de organização de ensino concernente à indissociabilidade entre conteúdo e método, no contexto da atividade de estudo, com base na obra de Davýdov. O pressuposto é de que a proposição davydoviana possa contribuir para repensarmos a Educação Matemática brasileira e o modo de organização de ensino.

O objeto de investigação consiste no modo de organização de ensino proposto por Davýdov $^{1}$ e colaboradores. Davýdov, estudioso da psicologia pedagógica soviética, pertenceu à terceira geração de pesquisadores da escola de Vigotski (CRESTANI, 2016). Comungava da concepção psicológica vigotskiana, cuja fundamentação é o Materialismo Histórico e Dialético. Mesmo vivendo em épocas distintas, ambos trouxeram contribuições para pensar o processo de aprendizagem e desenvolvimento humano. Por conseguinte, estabeleceram os princípios norteadores para a construção de uma nova concepção de ensino e aprendizagem. Para Vigotski (2000), a aprendizagem gera o desenvolvimento. Nessa direção, Davídov (1982) defende que a aprendizagem de conceitos empíricos promove o desenvolvimento do pensamento empírico, enquanto os científicos resultam no pensamento teórico.

A fim de promover o desenvolvimento do pensamento teórico dos estudantes, Davýdov organizou o ensino por meio de ações de estudo. Cada ação de estudo é constituída por um sistema de tarefas particulares. Estas foram publicadas em livros didáticos e de orientação ao professor por Davýdov (ДАВЫДОВ) e colaboradores, tais como Gorbov (ГОРБОВ), Mikulina (МИКУЛИНА) е Savieliev (САВЕЛЬЕВА). O material didático constitui a fonte de dados da presente pesquisa, em especial o livro didático de Matemática, desenvolvido por Davýdov e colaboradores, para o $2^{\circ}, 3^{\circ} \mathrm{e}$ o $4^{\circ}$ ano do Ensino Fundamental I (ДАВЫДОВ et al., 2012; ДАВЫДОВ et al., 2009; ДАВЫДОВ et al., 2011), e o livro de orientação ao professor para utilização dos referidos livros didáticos (ГОРБОВ; МИКУЛИНА; САВЕЛЬЕВА, 2003; ГОРБОВ; МИКУЛИНА; САВЕЛЬЕВА, 2009), todos publicados originalmente em língua russa.

\footnotetext{
${ }^{1}$ No decorrer do texto será utilizada a grafia Davýdov. Porém, ao se tratar de referência, será mantida a escrita conforme apresentada na obra: Davídov, Davýdov е Давыдов.
} 
O sistema integral, na presente investigação, consiste nas primeiras quatro ações de estudo para o ensino do conceito de divisão. As diferentes manifestações da relação universal ocorrem nas tarefas particulares. Desse modo, nos propomos investigar as manifestações da relação universal do conceito de divisão nas tarefas particulares no âmbito das quatro ações de estudo.

Trata-se de uma pesquisa bibliográfica, com respaldo nos pressupostos da Teoria Histórico-Cultural, mais voltada aos Fundamentos Matemáticos, Lógicos, Psicológicos, Didáticos e Filosóficos. O empenho foi no sentido de atingir a totalidade do sistema integral, expresso nas tarefas particulares, referentes às quatro ações de estudo para o ensino do conceito de divisão. Porém, não como uma soma de tarefas isoladas, mas como um todo articulado e relacionado dialeticamente entre si.

Na sequência apresentamos algumas tarefas correspondentes às quatro primeiras ações de estudo davydovianas, tal como estão propostas nos livros didáticos do segundo, terceiro e quarto anos do Ensino Fundamental I, e as desenvolvemos com base nos correspondentes livros de orientação ao professor. Optamos pelas quatro primeiras ações, dentre as seis propostas por Davýdov, porque nelas se encerra um microciclo de redução do concreto ao abstrato e ascensão do abstrato ao concreto. E esse microciclo pode ser pensado como um dos modos de organização do ensino em nosso país.

\section{Primeira ação de estudo: revelação dos dados que constituem a relação universal}

A primeira ação consiste na revelação dos dados que constituem a relação universal do conceito. Ela expressa a necessidade de realização da contagem de forma mais rápida que um a um, gerando a necessidade da unidade de medida intermediária, conforme a tarefa 1:

Tarefa 1 - No livro didático davydoviano, a proposição é que o professor apresente dois recipientes de mesma forma e tamanho, um com líquido (volume K) e outro vazio (Figura 1). Ambos sobre duas mesas distantes uma da outra. A tarefa consiste em transferir o líquido de um recipiente ao outro, sem retirá-los do lugar.

Figura 1 - $1^{\text {a }}$ tarefa, transferência de líquidos

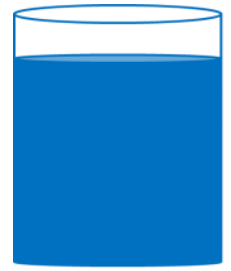

K
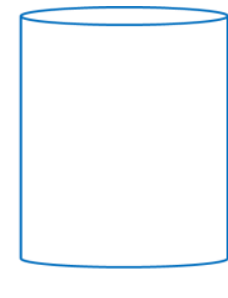

Fonte: Elaboração das autoras (2014) com base em Давыдов et al. (2012). 
O processo de resolução da tarefa é detalhadamente apresentado no livro de orientação ao professor (ГОРБОВ; МИКУЛИНА; САВЕЛЬЕВА, 2009): dada a condiçа̃o da tarefa, de permanência dos recipientes no local de origem, será necessário um terceiro recipiente para efetuar a transferência do líquido. O professor propõe um recipiente relativamente pequeno (recipiente com volume A). Inicia-se a transferência, bem como a problematização sobre o quão trabalhoso e demorado será o processo de transferência. Os estudantes são orientados para a necessidade de se utilizar outro recipiente (volume C), conforme a Figura 2.

Figura $2-1^{\text {a }}$ tarefa, unidade de medida básica (A) e unidade de medida intermediária (C)

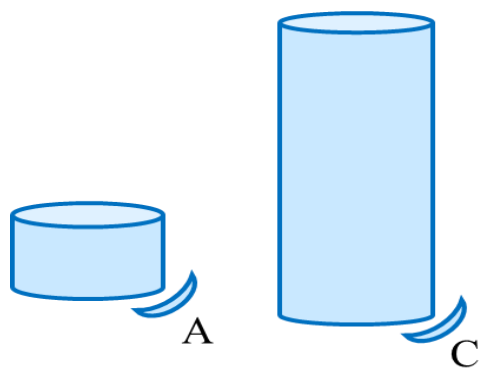

Fonte: Elaboração das autoras (2014) com base ет Давыдов et al. (2012).

O recipiente de volume $A$, denomina-se unidade de medida básica, e o de volume $C$, unidade de medida intermediária. Estes são de mesma forma que os recipientes apresentados inicialmente na tarefa, porém menores e com capacidades diferentes.

De acordo com o livro de orientação, a necessidade de realizar a transferência do líquido, de modo mais rápido, instiga os estudantes a refletirem sobre qual dos dois recipientes propiciará maior agilidade ao processo. A tarefa revela uma necessidade e a possibilidade de supri-la. O professor orienta para a seguinte conclusão: para uma transferência mais rápida, é necessário realizar a medição por meio da unidade de medida intermediária. Essa terminologia está relacionada ao seu tamanho médio, se comparada a menor (básica) e a maior (volume total de líquido a ser transferido).

No entanto, qual o valor da medida intermediária? Esta questão é levantada para que as crianças reflitam sobre a transformação da unidade de medida, que antes era a básica e que passa ser a intermediária. A sugestão é que se determine o valor da medida intermediária a partir da unidade de medida básica. Constata-se que a unidade de medida intermediária corresponde a quatro vezes a unidade de medida básica (Figura 3). 
Figura $3-1^{\text {a }}$ tarefa, relação quantitativa entre unidade de medida básica e intermediária
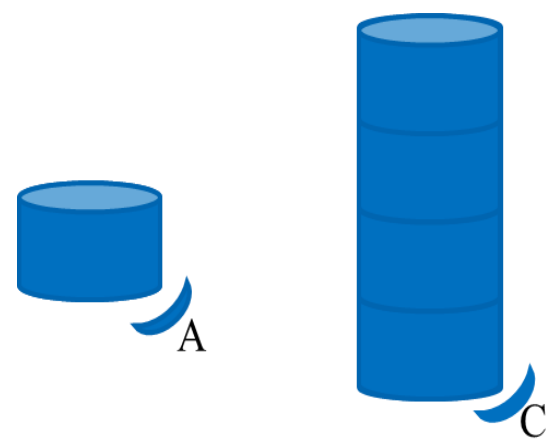

Fonte: Elaboração das autoras (2014) com base em Давыдов et al. (2012).

Portanto, os dados revelados são: medida do volume menor (unidade de medida básica); do intermediário (unidade de medida intermediária); e do volume maior (total de medidas básicas e intermediárias). Esses valores são desconhecidos e não estão dados explicitamente na tarefa. O cálculo dos referidos valores requer determinada relação entre os dados. Mas este não é o foco da primeira ação. Nela ocorre a revelação dos dados e a transformação: a unidade de medida, que inicialmente era básica, passou a ser intermediária, e a quantidade de vezes que ambas se repetem na medição. Estes dados compõem a relação universal do conceito de divisão.

De posse dos dados da tarefa, que emergiram durante o experimento objetal de transferência de líquidos, a próxima etapa, segunda ação de estudo, consiste na revelação e modelação da relação universal para o conceito em referência.

Segunda ação de estudo: modelação da relação universal na forma objetal, gráfica e literal

A modelação da relação universal ocorre na segunda ação de estudo. Aqui se modela a relação entre os dados revelados na primeira ação, concernente ao conceito de divisão. Trata-se da relação universal, do conceito, modelada nas formas objetal, gráfica e literal.

São diferentes representações da relação universal: inicialmente, na forma objetal, enquanto concreto sensorial, ponto de partida; posteriormente, nas formas gráfica e literal, como objetivação idealizada, abstração. A passagem do experimento objetal para o gráfico, e deste para o literal possibilita analisar a origem e o desenvolvimento do conceito que, considerando a continuidade na resolução da tarefa anterior, em síntese, seria assim realizado (Figura 4): 
Figura 4 - Modelo objetal, gráfico e literal

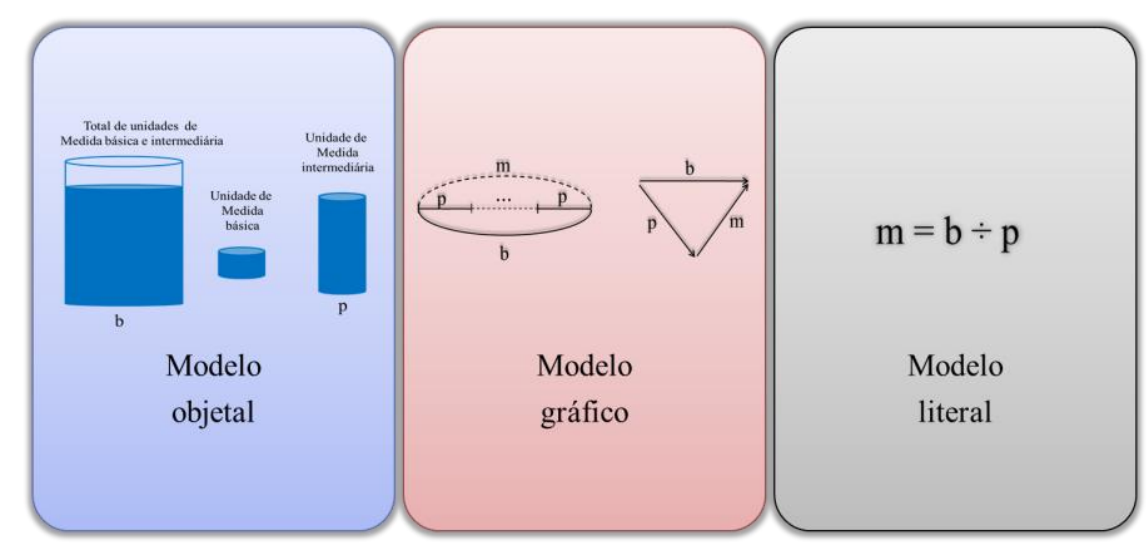

Fonte: Elaboração das autoras (2014).

Esse conjunto de abstrações sucessivas (objetal, gráfica e literal) compõe a abstração substancial. A abstração literal possibilita a generalização que fixa as características internas do objeto, não observáveis de maneira direta (DAVÍDOV, 1988).

O pensamento desenvolvido a partir desse movimento de abstração e generalização é denominado, por Davýdov (1982), de teórico. A modelação literal é expressão da reprodução, em nível teórico, da realidade objetiva. O elo entre a representação da modelação objetal e a literal consiste na representação da modelação gráfica.

Tarefa 2 - a tarefa é composta por três itens.

a) No primeiro são dispostos $M$ objetos em colunas compostas por três objetos cada (Figura 5). Como saber quantas colunas há ao todo? (ГОРБОВ; МИКУЛИНА; САВЕЛЬЕВА, 2003).

Figura $5-2^{\mathrm{a}}$ tarefa, figura parcialmente oculta e esquema de setas
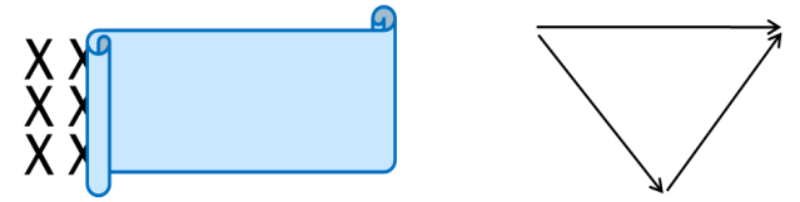

Fonte: Elaboração das autoras (2014) com base em Давыдов et al. (2009).

Os estudantes completarão o esquema e indicarão a operação aritmética a ser utilizada para a determinação da quantidade total de colunas. De acordo com o manual de orientação, durante a resolução da tarefa com os estudantes, o professor explica que, para determinar o total, é necessário contar de 3 em 3, pois a medida intermediária adotada consiste em três unidades de medidas básicas. Os estudantes registram os dados extraídos da análise da figura (representação objetal) e do próprio enunciado no esquema, que constitui a representação gráfica (Figura 5). 
Cada seta do esquema representa uma medida: a seta horizontal representa o total de unidades básicas que, neste caso, será representado por $M$. Ao lado da seta inclinada à esquerda é inserido o número representativo da medida intermediária, 3 (Figura 6). Ao lado da seta inclinada à direita e para baixo, completa-se com o valor correspondente à quantidade de medidas intermediárias que compõe o todo. Cada valor no esquema consiste na representação dos elementos que constituem as operações de multiplicação e divisão. O total de unidades básicas é, simultaneamente, produto e dividendo. A medida intermediária é o primeiro fator, na multiplicação, e divisor, na divisão. O terceiro elemento consiste no segundo fator da multiplicação, e o quociente da divisão.

Figura $6-2^{a}$ tarefa, figura parcialmente oculta e dados no esquema de setas
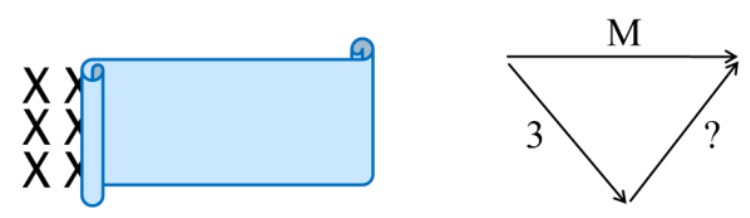

$$
\mathrm{M} \div 3=?
$$

Fonte: Elaboração das autoras (2014) com base em Давыдов et al. (2009).

Portanto, o valor desconhecido consiste na quantidade de colunas. A determinação da quantidade de vezes que a unidade de medida intermediária cabe no todo é possível por meio do conceito de divisão, cuja expressão representativa, neste caso, é: $\mathrm{M} \div 3=$ ?

b) o professor atribui um valor para $M(\mathrm{M}=21)$ e sugere um novo registro (Figura 7).

Figura $7-2^{a}$ tarefa, figura parcialmente oculta e esquema correspondente para $M=21$
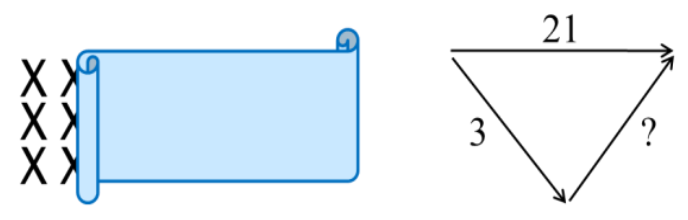

$$
21 \div 3=
$$

Fonte: Elaboração das autoras (2014).

A questão norteadora refere-se à quantidade de colunas que compõe a figura parcialmente oculta: quantas vezes a unidade de medida intermediária cabe no todo $(21 \div 3=$ ) ? A resolução ocorre na reta numérica (Figura 8), contexto geométrico que possibilita a determinação de quantas medidas intermediárias cabem no total de medidas básicas. Tal como o esquema, a reta numérica reproduz, teoricamente, a representação da relação universal. 


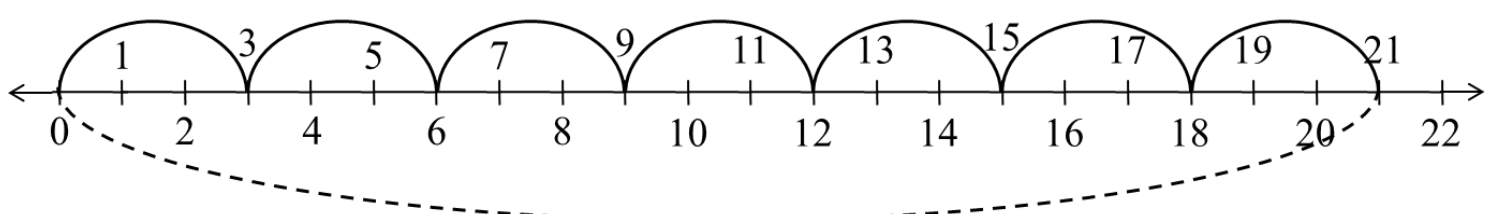

Fonte: Elaboração das autoras (2014).

$\mathrm{Na}$ reta numérica foram formados agrupamentos compostos por três unidades cada, representados pelos arcos. Nas 21 unidades básicas foi possível formar 7 agrupamentos.

c) o professor propõe aos estudantes, com base no item anterior, que determinem a quantidade de colunas, considerando $\mathrm{M}=17$. Os estudantes completam, no esquema os dados da tarefa: 17 unidades de medidas básicas (dividendo) distribuídas em colunas compostas por três unidades básicas (divisor), como mostra a Figura 9 (ГОРБОВ; МИКУЛИНА; САВЕЛЬЕВА, 2003).

Figura 9 - $2^{\mathrm{a}}$ tarefa, representação gráfica (esquema)

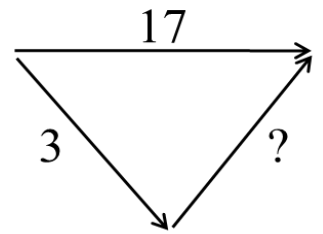

Fonte: Elaboração das autoras (2014).

Independentemente dos valores considerados, a relação é a mesma, portanto, universal. O esquema, representação geométrica da relação genética do conceito de divisão, o modelo gráfico, opera como instrumento para captar a essência, a qual possibilita a representação ideal no plano mental, dispensando, nesse estágio, o modelo objetal. $\mathrm{O}$ esquema representa a operação $17 \div 3$, que será resolvida com auxílio da reta numérica. Na reta numérica (Figura 10), o todo é formado por 17 unidades de medidas básicas (arco tracejado) e a medida intermediária (divisor), composta por três unidades básicas, será agrupada em arcos.

Figura $10-2^{a}$ tarefa, representação gráfica (reta numérica)

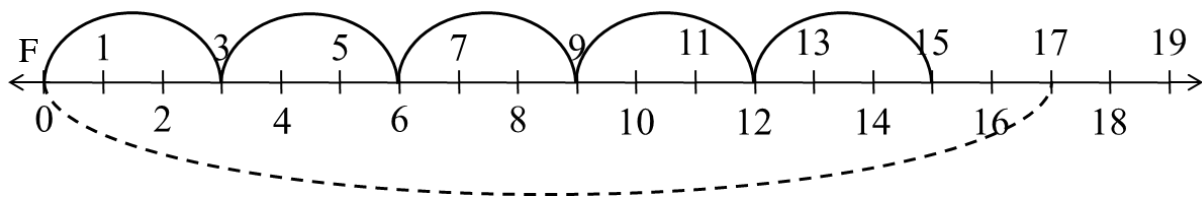

Fonte: Elaboração das autoras (2014). 
A unidade de medida intermediária cabe inteira, cinco vezes, no total de unidades de medida básica e restam duas unidades sem serem agrupadas (Figura 10). O professor explica que, em divisões com resto, deve-se colocar a quantidade de medidas intermediárias que cabem na grandeza e, ao lado, entre parênteses, a quantidade de medidas básicas restantes (Figura 11):

Figura $11-2^{\mathrm{a}}$ tarefa, representação gráfica (esquema)
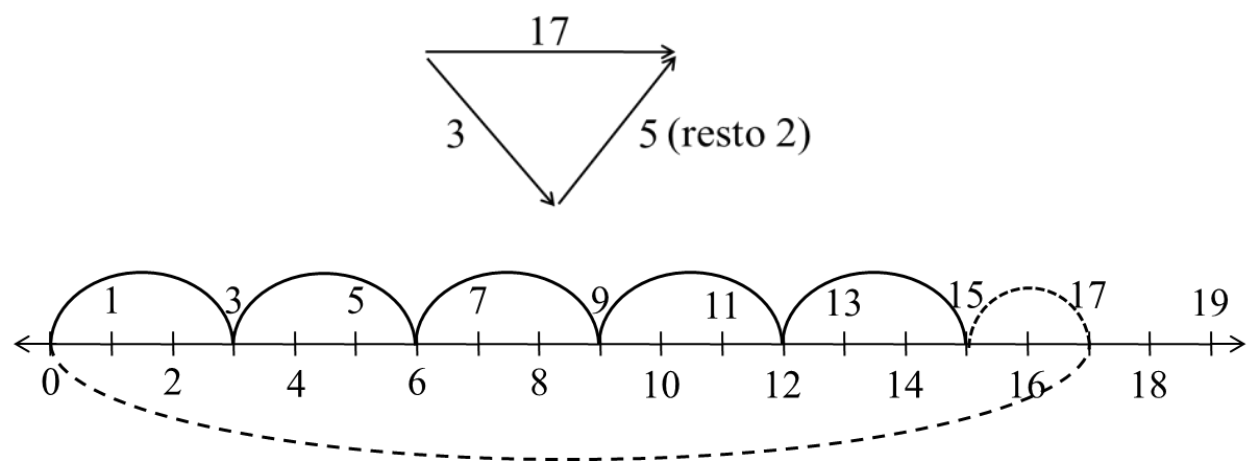

Fonte: Elaboração das autoras (2014).

O professor completa no quadro: $17=(3 \times 5)+2$. E enfatiza que a medida intermediária pode não caber exatamente o número inteiro de vezes no total de medidas básicas. Nesse caso, determina-se o total que couber inteiro e, em seguida, mediremos as quantidades de unidades de medidas básicas restantes. Ao número de medidas básicas restantes denomina-se resto (ГОРБОВ; МИКУЛИНА; САВЕЛЬЕВА, 2003).

Em continuidade ao processo de abstração da relação universal, da reprodução teórica do conceito de divisão, a próxima tarefa prevê a modelação algébrica.

Tarefa 3 - o professor sugere que os estudantes estabeleçam relações entre os esquemas (Figura 12).

Figura $12-3^{\text {a }}$ tarefa, esquema abstrato
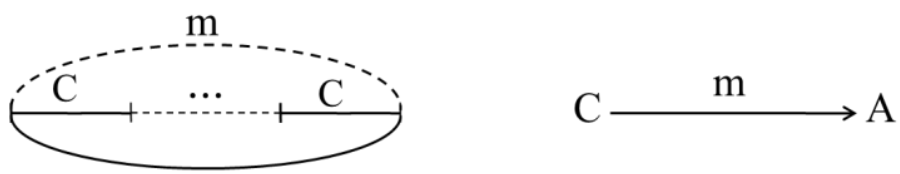

A

Fonte: Elaboração das autoras (2014) com base ет Давыдов et al. (2009).

As representações (Figura 12), ainda que aparentemente diferentes, são constituídas pelos mesmos elementos: $C$ é a medida intermediária (divisor), $m$ é a quantidade de vezes que $C$ se repete (quociente), e $A$ é o total de unidades básicas (dividendo). As representações indicam que $A$ corresponde $m$ vezes de $C$. Em outras palavras, o inteiro $(A)$ é composto de $m$ partes iguais $C$, ou o 
inteiro $(A)$ é dividido em $m$ partes iguais $C$. A medida $C$ cabe na grandeza $A m$ vezes. Trata-se de uma tarefa que sintetiza o movimento de modelação realizado até o momento, porém, agora na forma literal.

c) Para finalizar a tarefa o professor propõe a reflexão dos modelos gráfico e literal da divisão, conforme a Figura 13.

Figura $13-4^{\mathrm{a}}$ tarefa, modelo gráfico e literal

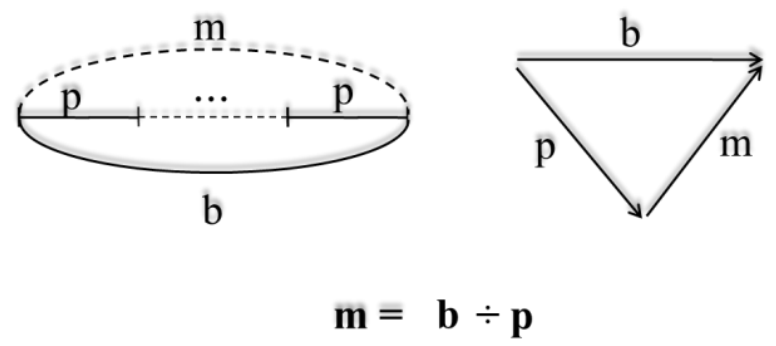

Fonte: Elaboração das autoras (2014) com base em Давыдов et al. (2009).

Finalmente, a relação universal atinge o nível máximo de abstração: $\mathrm{m}=\mathrm{b} \div \mathrm{p}$. Esta é expressão do experimento objetal ponto de partida, mas em nível teórico. Durante o movimento de redução, alguns elementos foram abstraídos, tais como os objetos, suas respectivas grandezas, os esquemas, a reta numérica, entre outros. Porém, permaneceu o essencial, os dados que constituem a relação universal do conceito de divisão, pois, na Figura 13, $b$ representa o total de unidades básicas (dividendo); $p$, a unidade de medida intermediária (divisor); e $m$, a quantidade de vezes que $p$ se repete, ou seja, o quociente. Isso porque, para determinarmos o total de partes que se repetem, é necessário dividir o todo (dividendo) pelo valor da medida intermediária (divisor). O modelo literal expressa as características internas do conceito, cuja transformação ocorre na terceira ação de estudo.

Terceira ação de estudo: transformação do modelo da relação universal para o estudo de suas propriedades

$\mathrm{Na}$ terceira ação ocorre a transformação do modelo para possibilitar o estudo das propriedades do conceito. Na especificidade deste, ocorre a transformação do modelo referente à relação universal do conceito de divisão. Em outras palavras, as propriedades conceituais são reveladas por meio das relações e conexões mútuas realizadas pelos estudantes, sob a orientação do professor. Tais propriedades referem-se ao movimento interno, essencial, do conceito.

A partir da análise das propriedades, realizada nesta quarta ação, cria-se a base para a formação de um procedimento, válido para a realização das tarefas que serão apresentadas na quarta 
ação. $\mathrm{O}$ estudo das propriedades consiste nas transformações decorrentes da relação universal do conceito, as múltiplas transformações que podem ocorrer no modelo representativo da relação universal, conforme a tarefa a seguir.

Tarefa 4 a) - A partir das informações (Figura 14), o professor propõe aos estudantes que completem o esquema de setas e determinem o valor desconhecido, com base na relação universal do conceito, modelada na ação anterior.

Figura $14-5^{\text {a }}$ tarefa, representação dos dados no esquema de setas
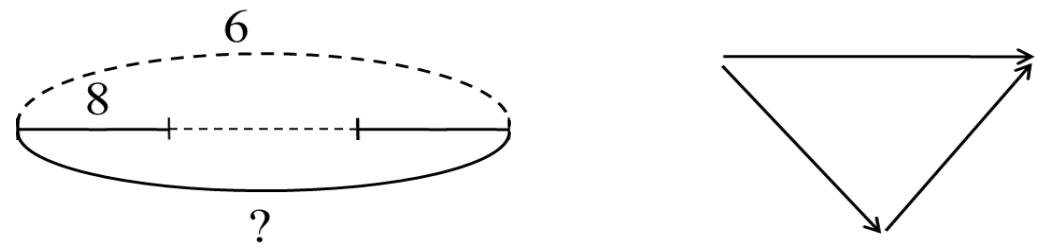

Fonte: Elaboração das autoras (2014) com base ет Давыдов et al. (2009).

Segundo a Figura 14, o número 8 representa a unidade de medida intermediária; e 6, a quantidade de vezes que 8 se repete. $\mathrm{O}$ valor desconhecido é o todo (total de unidades de medida básica). Portanto, a operação a ser realizada é a multiplicação. Os estudantes completam o esquema, segundo a Figura 15:

Figura $15-5^{\mathrm{a}}$ tarefa, representação da operação de multiplicação 8 x 6 no esquema

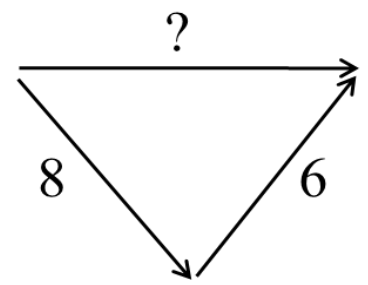

Fonte: Elaboração das autoras (2014).

Tarefa 4 b) Na sequência, os estudantes são orientados a completar o esquema de setas (Figura 16) e determinar o valor desconhecido.

Figura $16-5^{\text {a }}$ tarefa, representação no esquema setas dos dados contidos na reta

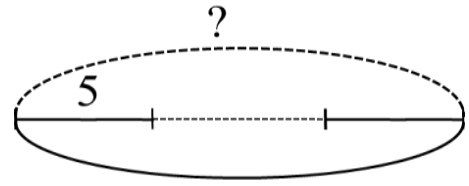

35

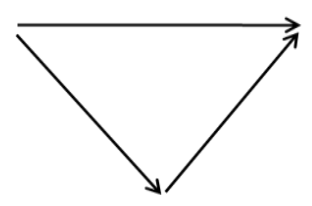

Fonte: Elaboração das autoras (2014) com base em Давыдов et al. (2009). 
Com base nas informações apresentadas, o valor 5 representa a unidade de medida intermediária (divisor); e 35, o total de unidades de medida básica (dividendo). Assim, têm-se o dividendo e o divisor. $\mathrm{O}$ valor desconhecido é o quociente (Figura 17).

Figura $17-5^{\mathrm{a}}$ tarefa, representação gráfica da operação de divisão

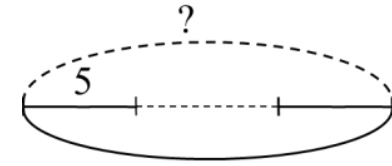

35

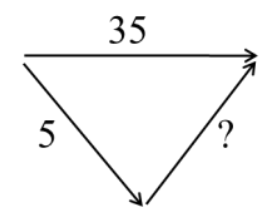

$35 \div 5=$

Fonte: Elaboração das autoras (2014).

A síntese a ser elaborada é que 5, multiplicado por 7, resultará em 35. Ou, ainda, 5 cabe 7 vezes em 35 (Figura 18).

Figura $18-5^{\mathrm{a}}$ tarefa, representação gráfica da operação de divisão

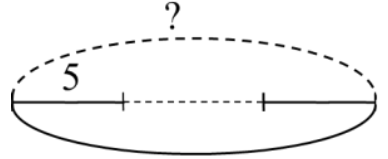

35

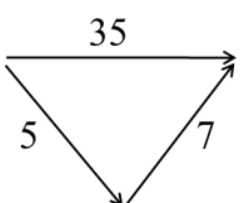

$35 \div 5=7$

Fonte: Elaboração das autoras (2014).

Tarefa 4c) O terceiro item (Figura 19) é semelhante aos anteriores, porém com valores distintos.

Figura $19-5^{a}$ tarefa, representação dos dados no esquema

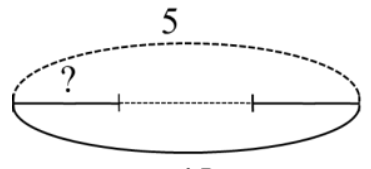

45

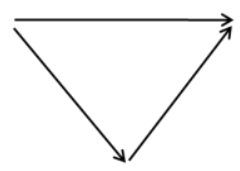

Fonte: Elaboração das autoras (2014) com base ет Давыдов et al. (2009).

Tem-se o total de unidades de medida básica e a quantidade de vezes que a unidade de medida intermediária cabe no todo. A determinação recai sobre o valor da unidade de medida intermediária (Figura 20).

Figura $20-5^{\mathrm{a}}$ tarefa, representação gráfica da operação de divisão

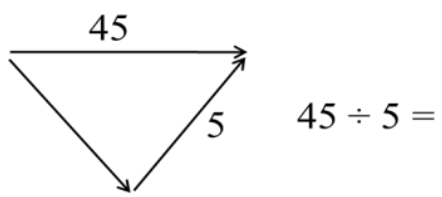

Fonte: Elaboração das autoras (2014). 
O professor explica que, para determinar um dos fatores, divide-se o dividendo pelo outro fator conhecido, $45 \div 5$. O resultado é 9 , como evidencia o esquema (Figura 21 ):

Figura $21-5^{\mathrm{a}}$ tarefa, representação gráfica da operação de divisão
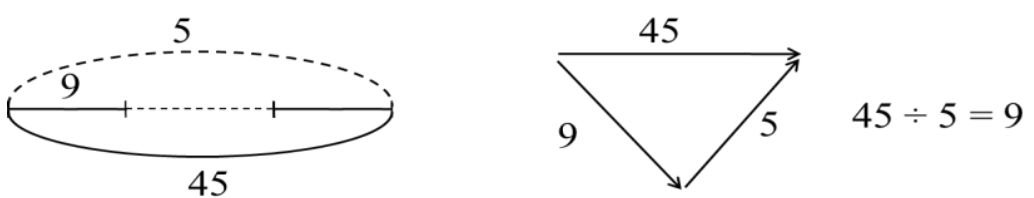

Fonte: Elaboração das autoras (2014).

Em cada uma das situações anteriores (itens a, b e c), o valor desconhecido refere-se a um elemento distinto da relação universal: na primeira foi o total de unidades básicas (produto); na segunda, o total de unidades intermediárias (quociente); e, na terceira, o valor da própria medida intermediária. Em decorrência, a relação universal pode ser transformada em três modelos distintos, conforme a Figura 22:

Figura $22-5^{a}$ tarefa, quadro-síntese da transformação do modelo

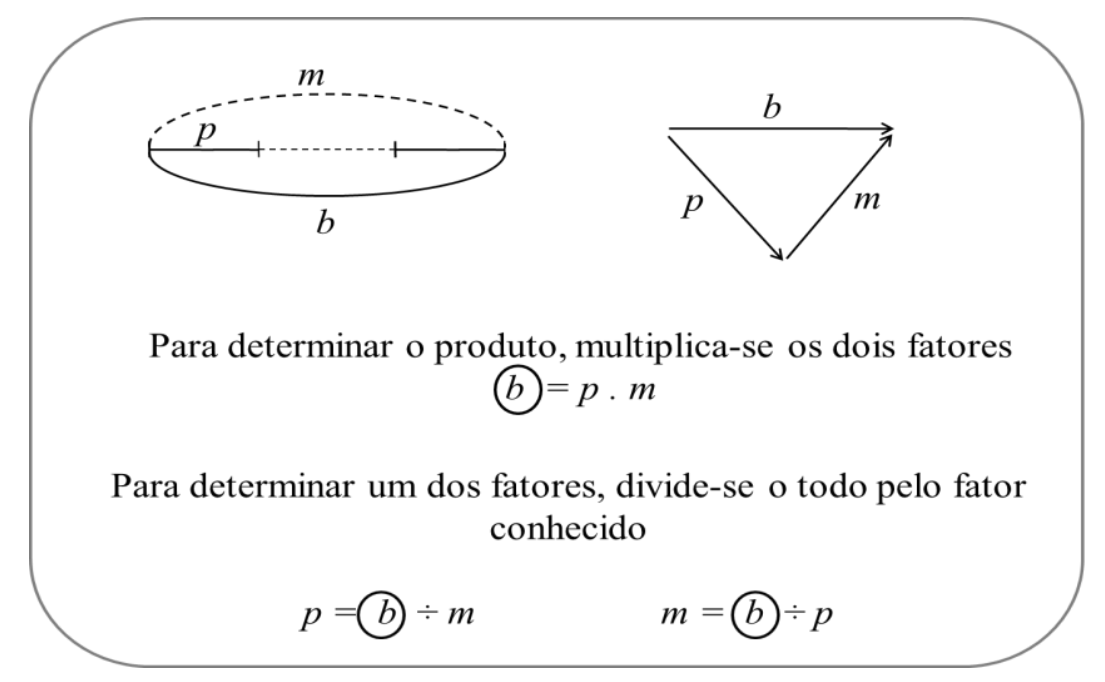

Fonte: Elaboração das autoras (2014) com base em Давыдов et al. (2009).

A transformação da relação universal possibilita o estudo das propriedades do conceito de divisão na próxima ação.

Quarta ação de estudo: construção de um sistema de tarefas singulares a partir da relação universal

Na quarta ação constrói-se um sistema de tarefas singulares a partir da relação universal revelada na primeira ação, modelada na segunda e transformada na terceira. Nesta, ocorre a análise das propriedades da relação universal em suas manifestações singulares. Neste estágio, os estudantes 
analisam, com a orientação do professor, os dados da tarefa particular, captam a conexão universal e aplicam a relação na resolução.

Nesta ação ocorre a passagem do universal para o particular e singular. É neste estágio que ocorre a sistematização da padronização das medidas. Passa-se a singularizar as ações por meio de representações numéricas e suas respectivas unidades (metro seus múltiplos e submúltiplos).

Tarefa 5: A tarefa consiste no cálculo do valor desconhecido (Figura 23):

Figura 23 - $7^{\mathrm{a}}$ tarefa, representação gráfica da conversão de medidas
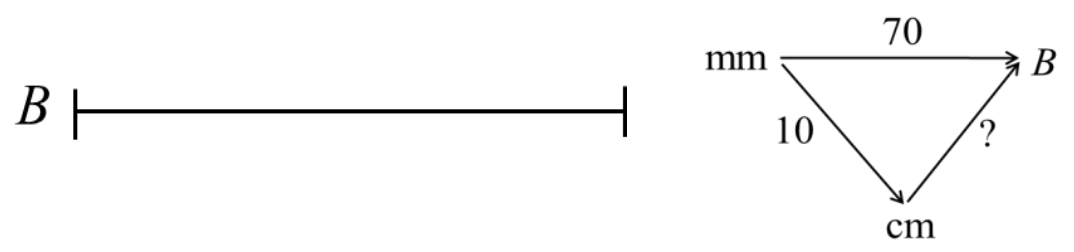

Fonte: Elaboração das autoras (2014) com base em Давыдов et al. (2009).

$\mathrm{Na}$ ilustração (Figura 23) consta um segmento, cujo comprimento mede $B$ (o todo). No esquema há o registro da medida do segmento (70 milímetros). É necessário determinar o valor da medida intermediária para proceder ao cálculo do valor desconhecido. Trata-se da relação entre centímetros e milímetros. Como um centímetro é composto por 10 milímetros, este será o valor da medida intermediária. Quantas medidas intermediárias $(10 \mathrm{~mm})$ cabem no comprimento $B$ ? $\mathrm{O}$ resultado é obtido por meio da operação de divisão: $70 \div 10=7$ (Figura 24).

\section{Figura $24-7^{\mathrm{a}}$ tarefa, representação gráfica da operação de divisão}

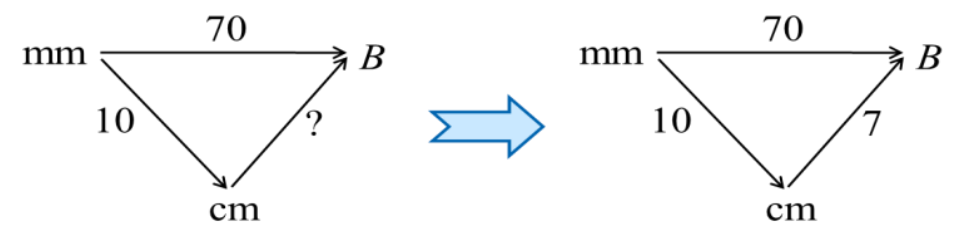

Fonte: Elaboração das autoras (2014).

Temos todos os elementos da relação universal, porém, no contexto de uma situação singular: unidade de medida básica (1 centímetro), unidade de medida intermediária (10 milímetros), total de unidades intermediárias (7 centímetros) e total de unidades básicas (70 milímetros).

Na sequência, o professor orienta os estudantes no procedimento de verificação do resultado por meio da medição do segmento com a régua. Assim, ocorre o trânsito da relação universal para a explicação das manifestações singulares, na especificidade da tarefa em análise, a expressão aritmética da medida $B$. Esta surge a partir de uma unidade de medida particular, o metro 
e seus submúltiplos. A partir da relação universal deduzimos as condições e métodos de medição da grandeza comprimento. Da relação geneticamente inicial germinam as relações particulares que possibilitam a resolução de situações singulares.

\section{Considerações Finais}

Direcionamos nosso olhar para o modo de organização de ensino proposto por Davýdov e colaboradores. Nele, elegemos como objeto de estudo a relação universal do conceito de divisão e sua objetivação nas tarefas particulares elaboradas por Davýdov e colaboradores no contexto das ações de estudo.

Constatamos que a relação universal do conceito de divisão é constituída pelos seguintes elementos: unidade de medida básica, intermediária e o total de ambas. A relação essencial do conceito de divisão consiste, pois, na determinação da quantidade de vezes que o divisor (unidade de medida intermediária) cabe no dividendo (total de unidades de medida básica e intermediária).

Esta relação, revelada na primeira ação de estudo, no plano objetal, manifesta-se em todas as ações seguintes. Tais manifestações passam por sucessivas abstrações, modificando, assim, sua representação, inicialmente no plano objetal, em seguida, na forma gráfica e, finalmente, atinge o modelo algébrico. Este é a abstração máxima do processo de redução do concreto ponto de partida. Por outro lado, no concreto ponto de chegada ocorre a generalização conceitual, por meio da qual a relação essencial pode ser aplicada nas diversas singularidades, dentre elas, a sistematização das medidas padronizadas.

Cabe enfatizar que Davýdov desenvolveu sua obra no contexto russo, no momento histórico em que a educação escolar primava pelo desenvolvimento de conhecimentos empíricos, tal como ocorre em nosso país atualmente (ROSA, 2012), e que, mesmo assim, foi capaz de reverter esse quadro e propiciar aos estudantes, que se utilizaram do ensino organizado por ele e seu grupo, a apropriação de conhecimento científico e o desenvolvimento do pensamento teórico (DAVÝDOV, 1982). Disso decorre que, de acordo com o autor em referência, ao modificar os métodos de ensino e os conteúdos, pode-se realizar possíveis transformações no processo de ensino e aprendizagem.

Considerando a semelhança entre o atual modo de organização de ensino brasileiro com aquele desenvolvido na Rússia, no momento em que Davýdov produziu sua obra (GALDINO, 2016; MATOS, 2017), vislumbramos a possibilidade de repensar a educação brasileira a partir das reflexões davydovianas com vistas à apropriação dos conceitos científicos e ao desenvolvimento do pensamento teórico. 
Agradecimentos: A pesquisa que gerou o presente artigo contou com financiamento do Conselho Nacional de Desenvolvimento Científico e Tecnológico (CNPq) e Fundação de Apoio à Pesquisa Científica e Tecnológica do Estado de Santa Catarina (FAPESC).

\section{Referências}

CRESTANI, S. Organização do ensino de Matemática na perspectiva do desenvolvimento do pensamento teórico: uma reflexão a partir do conceito de divisão. 2016. 126 f. Dissertação (Mestrado em Educação) - Universidade do Sul de Santa Catarina, UNISUL, Tubarão, 2016.

DAVÍDOV, V. V. La enseñanza escolar y el desarrollo psíquico: investigación teórica y experimental. Tradução de Marta Shuare Moscú: Editorial Progreso, 1988.

DAVÝDOV, V. V. Tipos de generalización en la enseñanza. $3^{\text {a }}$ edição. Habana: Editorial Pueblo y Educación, 1982.

GALDINO, A. P. S. O conhecimento matemático de estudantes do $3^{\circ}$ ano do ensino fundamental sobre o conceito de multiplicação: um estudo com base na Teoria HistóricoCultural. 2016. 110 f. Dissertação (Mestrado em Educação)-Universidade do Sul de Santa Catarina, Tubarão, 2016.

MATOS, C. F. Modo de organização do ensino de matemática em cursos de pedagogia: uma reflexão a partir dos fundamentos da Teoria Histórico-Cultural. 2017. 139 f. Dissertação (Mestrado em Educação) - Universidade do Sul de Santa Catarina, Tubarão, 2017.

ROSA, J. E. Proposições de Davydov para o ensino de matemática no primeiro ano escolar: inter-relações dos sistemas de significações numéricas. 2012. 244 f. Tese (Doutorado em Educação). Área de concentração: Educação Matemática - Universidade Federal do Paraná, Curitiba, 2012.

VIGOTSKI, L. S. A construção do pensamento e da linguagem. Tradução de Paulo Bezerra. São Paulo: Martins Fontes, 2000.

ДАВЫДОВ, В. В. О. et al. Математика, Учебник для 2 класса начальной школы. В 2-х кн. (Система Д. Б. Эльконина - В. В. Давыдова).11- е изд. - М.: ВИТА-ПРЕСС, 2012. - 96 с.: ил.

ДАВЫДОВ, В. В. О. et al. Математика: Учебник для 3 класса нач. школы (Система Д. Б. Эльконина - В. В. Давыдова).В 2-х кн. 7-е изд. - М.: ВИТА-ПРЕСС, 2009. - 112 с.: ил.

ДАВЫДОВ, В. В. О. et al. Математика: Учебник для 4 класса нач. школы (Система Д. Б. Эльконина - В. В. Давыдова).В 2-х кн. 8-е изд. - М.: ВИТА-ПРЕСС, 2011. - 144 с.: ил.

ГОРБОВ, С. Ф. МИКУЛИНА Г. Г.; САВЕЛЬЕВА О. В. . Обучение математике. 2 класс: Пособие для учителей начальной школы. 2-е ида. перераб. - М.:ВИТА-ПРЕССб, 2009.

ГОРБОВ, С. Ф. МИКУЛИНА Г. Г.; САВЕЛЬЕВА О. В. . Обучение математике. 3 класс: Пособие для учителей начальной школы. 2-е ида. перераб. - М.:ВИТА-ПРЕССб, 2003. 